\title{
DIREITO, JURISPRUDÊNCIA E JUSTIÇA NO PENSAMENTO CLÁSSICO (GRECO-ROMANO)
}

\author{
LAW, JURISPRUDENCE AND JUSTICE IN CLASSIC THOUGHT (GREEK-ROMAN)
}

\author{
Ignacio Maria Poveda Velasco
}

\begin{abstract}
Resumo:
O Autor disserta sobre o Direito como Ciência, iuris prudentia; o Direito em sentido objetivo, sunn ou ipsa res iusta, a norma agendi, conceitos que sugerem mudanças significativas com o passar dos tempos.
\end{abstract}

Palavras-chave: Jurista. Direito. Jurisprudência. Ciência do Direito.

Abstract:

The Author writes on Law as a science, iuris prudentia, law in objective sense, summ or ipsa res iusta, norma agendi, concepts that suggest meaningful changes across the years.

Keywords: Jurist. Law. Jurisprudence. Science of Law.

\section{Considerações preliminares}

As palavras são, ou deveriam ser, a roupagem das idéias, canais por onde escoam os conceitos com os quais nos expressamos. Esses conceitos por vezes sofrem mudanças com o tempo e as palavras passam, então, a traduzir significados diferentes daqueles que tiveram em seu nascedouro.

Modernamente, usamos os termos "jurista" "Direito" "jurisprudência" ou mesmo "justiça" num sentido por vezes distinto daquele cmpregado pclos antigos. Assim, numa linguagem atual o jurista seria o grande conhecedor do Direito, o operador reconhecido pelo ambiente profissional e que, nesse sentido, é consagrado pela midia. Fala-se, então, do "jurista Fulano de Tal e não simplesmente do advogado" Fulano de Tal, mesmo que ele seja, de fato e apenas um profissional dedicado de alma e corpo à advocacia. O mesmo pode-se dizer de um magistrado ou de um procurador de Justiça de destaque no cenário jurídico nacional. Falar tão-somente em advogado ou juiz parece "dizer pouco" desses grandes profissionais. Contudo, como veremos mais adiante, não foi esse o sentido "original" (ou seja, aquele que teve na origem, em seu nascedouro) do vocábulo jurista, e nem o usado por muitos e muitos séculos.

Professor Titular de História do Direito da Faculdade de Direito da Universidade de São Paulo c Presidente dos Cursos de Pós-Graduação da Faculdade de Direito da Universidade de São Paulo .Membro do Conselho Editorial da Revista da Faculdade de Direito da tiniversidade de São Paulo. 
Em relação ao termo "jurisprudência" podemos observar a mesma mutação semântica. Para nós, hoje, designa a interpretação reiterada que os tribunais dão a determinada lei, nos casos concretos que são submetidos a seu julgamento. Também aqui se pode afirmar que não era esse o sentido com o qual foi utilizado na Roma antiga. berço reconhecido da ocidental Ciência do Direito.

Pode se objetar que pouco importa saber qual o sentido "original" desses e outros vocábulos, pois o relevante seria conhecer o seu sentido atual. Não é bem assim. Em primeiro lugar por que a compreensão do sentido "genuíno" (do latim genuinus. que por sua vez vem de genui, pretérito de gigno, ou seja "gerado" "criado"; sinônimo, por tanto. de "original") das palavras nos ajuda a melhor empregá-las. E em segundo lugar por que, por vezes, o emprego moderno dos termos tem introduzido alteração substancial nos mesmos, levando a visões reducionistas ou mesmo distorcidas dos conceitos que traduziam em seu início. É o caso. especialmente, da palavra "direito" cujos diversos significados tantos problemas suscita.

O que nós chamamos atualmente "Direito" era designado pelos romanos através do vocábulo ius que, na lição de Ulpiano, deriva da iustitia: est cutem a iustitia appellatum (Ulp. I inst., D.1, 1, 1 pr.).

Mas. etimologicamente falando, "Direito" vem de ius? "Direito" em português: derecho, em espanhol; diritto, em italiano; droit. em francês... Sempre traduzindo a idéia de algo reto, direito. que não é torto. É o mesmo sentido de termos não-latinos como o alemão recht ou o inglês right.

Analisando os vocábulos das línguas neolatinas é fácil concluir que não derivam de ius. Seriam uma evolução da palavra latina derectum, a evocar o fiel da balança que, em face do equilíbrio dos pratos, imagem da igualdade da justiça. fica "reto". rectum, no meio. E dai a palavra derectum (de+rectum), Direito.

2.

O Direito como ciência: a iuris prudentia

A atividade dos jurisconsultos da Roma antiga, que interpretavam (interpretatio iuris) as normas de Direito, dando o seu parecer sobre problemas concretos da vida que thes eram apresentados, recebeu o nome de iuris prudentia. Pelo que tem de criadora, essa atividade dos juristas passou a constituir uma ciência, a Ciência do Direito da qual os romanos são, reconhecidamente, os fundadores.

É de Ulpiano a célebre definição, recolhida no Digesto (Ulp. 1 reg. D. 1, 1. 10,2): Iuris prudentia est divinarum atque humanarum rerum notitia, iusti atque iniusti 
scientia - a jurisprudência é o conhecimento das coisas divinas e humanas, a ciência do justo e do injusto. Vale dizer, a ciência do que é conforme ou desconforme ao Direito (ius).

$\mathrm{Na}$ época clássica, a partir do séc. I d.C., os principais jurisconsultos foram agraciados com o ius respondendi ex auctoritate principis, o direito de responder em virtude da autoridade do imperador, e, por conta disso, seus pereceres (responsa prudentium) passaram a ser considerados fonte do Direito.

Jurisprudência. Ciência do Direito. Interessante notar como a tradição italiana é fiel a esse sentido original, genuíno, do termo, quando designa o que nós chamamos "faculdade de Direito" com a expressão "facoltà di giurisprudenza": lugar onde se ensina e se estuda a jurisprudência, a Ciência do Direito.

Iuris prudentia: atividade dos iuris prudentes ou, literalmente, "prudência dos juristas" Mas. afinal, retomando o comentário inicial: o que é ser jurista? Quem é jurista? Etimologicamente falando, jurista é aquele que se dedica ao ius, ao Direito, assim como futebolista é aquele que se dedica ao futebol ou dentista aquele que se dedica a tratar dos dentes. Nesse sentido, então, mais básico ou prosaico, jurista é todo aquele que se devota à Ciência do Direito, que estuda e conhece o Direito, o homem do Direito, já chamado na Idade Média de "letrado", porque nessa época littera(ae) era o nome dado às leis ou textos jurídicos.

No que consiste o conhecimento do jurista? O que é que ele conhece? Como é a sua ciência? Há dois tipos de conhecimento ou ciência: a ciência especulativa e a ciência prática.

A ciência especulativa (do latim speculum - espelho) é aquela que reflete a realidade, mas sem fazê-la ou construi-la. Tomemos o exemplo da pintura: podemos ter um conhecimento aprofundado das diversas escolas (pintura clássica, impressionismo, cubismo, etc.), dos grandes pintores. dos seus quadros, das técnicas e materiais por eles usados... Tudo isso pode constituir um saber ou ciência meramente especulativa, que em si não nos habilita a pintar. Para tal deveremos ter o conhecimento prático ou a arte da pintura. Poderíamos dizer o mesmo em matéria de futebol: as intermináveis mesas redondas da nossa televisão, após a rodada do fím de semana, manifestam um conhecimento do assunto, teórico podemos dizer. que por si só não credencia os prolixos comentaristas a pleitear uma vaga na seleção brasileira. Jogar bem futebol é outra coisa, é arte reservada a alguns poucos.

A ciência prática ou arte (do latim ars) é o "saber fazer" uma determinada coisa ou atividade. dominar a "maneira" ou o "modo" de realizá-la. Dessa forma falamos na arte da pintura e do pintor, na arte do futebolista, na arte do cinema, e assim por diante. 
O conhecimento do jurista, a sua ciência é uma arte. Nesse sentido, a célebre definição de Celso, recolhida por Ulpiano e transcrita pelos compiladores de Justiniano bem no inicio do Digesto (Ulp. l inst., D. 1, I, I pr.): a Ciência do Direito é ars boni el aequi, a arte do bom e do justo ou, se se quer, do eqüitativo. que nada mais é do que o justo no caso concreto.

No que consiste a arte ou conhecimento prático do jurista? O que é que ele sabe ou deve saber fazer? O conhecimento prático do jurista consiste em descubrir o que é "justo" numa relação social concreta. Jurista é aquele que conhece a respeito do justo e do injusto (iusti atque iniusti scientia, diziamos antes), e não-somente do "legal" e do "ilegal" Seu saber ou conhecimento próprio é a ciência do justo, ou Ciência do Direito ou jurisprudência. porque nesse sentido "o justo" é igual a "direito" É assim que nos expressamos na linguagem coloquial, mesmo sem atentar para isso. Dizemos, por exemplo, fazendo menção a um contrato de locação. que é "direito" do locatário ocupar o imóvel alugado: isso é "o justo" no caso concreto de um contrato dessa natureza. Pelo contrário, se se viola ou ataca um direito dizemos que isso é "injusto": o "injusto" é a "lesão do direito"

Para quê existe a arte do Direito? Qual a sua finalidade? A arte do Direito existe para satisfazer, pelas mãos de seus artífices (juizes, advogados, promotores, etc.) a necessidade de justiça num caso concreto, para resolver uma controvérsia concreta. Num processo qualquer, procura-se que o juiz diga com autoridade, sentencie o que é que corresponde a cada uma das partes litigantes. Por exemplo, que tal parte da herança de José corresponde a João, que a está pleiteando; ou que efetivamente Pedro deve tal quantia de dinheiro a Paulo, e por isso deve saldar a divida, etc.

O juiz sentencia (e sentenciar é dizer: sententiam dicere) em relação àquilo que corresponde a cada um. Sentencia sobre o que é "o seu" (suım) de cada um.

3. O Direito em sentido "objetivo": o summ ou a ipsa res iusta

É amplamente conhecida a definição romana da justiça como "dar a cada um o seu" ou "dar a cada um o que lhe corresponde" É o suum cuique tribucre, de que fala Ullpiano (Ulp. I reg., D. I, 1, 10. I).

$\mathrm{Na}$ prática profissional. todos os operadores do Direito. como servos da Justiça que são, procuram, ou deveriam procurar, esse suım cuique tribuere, dar a cada um o que é seu. Isto é válido não apenas para o juiz ou o promotor, mas também para o advogado. Na consecução da justiça e na defesa do interesse de seu cliente, o adrogado deve pleitear aquilo que entende ser "o seu" de seu cliente, o "direito" dele, procurando 
sempre a solução mais favorável. Mesmo que, no caso de um réu confesso, esse suum fique reduzido ao julgamento justo, com a ponderação de eventuais atenuantes, ao qual, como cidadão, tem direito e que, por isso, "Ihe é devido" ou "Ihe corresponde"

Essa acepção do termo "direito", entendido como "o seu" (suum), "o que é devido". "o justo" "o que corresponde a alguém" é o sentido primeiro da palavra, o "genuino" aquele com o qual nasceu entre os juristas romanos. É o Direito em sentido "objctivo", que os juristas medievais. desenvolvendo o pensamento clássico, irão definir como a ipsa res iusta: a própria coisa devida. "Objetivo" por que evoca "objeto" ou seja por que diz respeito à própria coisa (ns), àquilo que é devido ou corresponde.

A idéia de "Direito" assim entendida não se confunde, portanto, com a de "lei" ou "norma", embora exista untre elas, como é obvio, uma interligação clara. A lei é o Direito em sentido "positivo" do qual falaremos mais adiante, ou seja a norma posta por quem tem autoridade, para regular determinados comportamentos sociais.

O Direito em sentido "objetivo" nos leva à idéia de "atribuição" Falar num suum, num "seu" num "meu" ou num "dele" supõe reconhecer que as coisas estão repartidas, atribuídas. Isto, de resto, é uma constatação pura e simples que pode ser feita, bastando para isso olhar ao redor. Na sociedade, há coisas que são de um ou de outro, que correspondem a este ou àquele: o carro do Antonio, o livro da Maria, etc.

Caberia indagar por que razão existe essa repartição ou atribuição das coisas, e, na seqüência, do que ela decorre.

Pode-se pensar que a apropriação ou atribuição é consequiência da escassez: como não há de tudo para todos, tornar-se-ia necessário reter algo para si. A escassez, conceito determinante sem dúvida na economia para a fixação de preços, por exemplo. tem influência no processo de apropriação no âmbito de uma determinada sociedade, mas não é o fator decisivo ou último: mesmo num hipotético cenário de "superabundância", haveria apropriação ou atribuição.

Imaginemos, ad argumentandum. que exista superabundância de tudo, de automóveis, por exemplo. Desse modo, se a apropriação fossc decorrência necessária da escassez, não haveria um carro yue fosse "meu": poderia, pois, entrar no primeiro carro que encontrasse na porta da Faculdade e sair andando com ele. Mas, suponhamos que eu tivesse deixado no carro com o qual eu vim da minha casa (aliás, num cenário de superabundância, seria incorreto falar da "minha" casa...) uma mala com as minhas roupas, para viajar, e que esse carro tenha sido levado por um terceiro. Na lógica da superabundância. isso não representaria nenhum problema, bastando que eu pegasse a primeira mala com roupas que aparecesse... Dá para perccber que, por ai não vamos a parte alguma. 
Mesmo considerando o papel que a escassez tem na apropriação das coisas no âmbito social, podemos entender que a atribuição dos bens e a sua repartição é decorrência do próprio modo de ser do homem. Se não houvesse escassez. talvez não haveria disputas (processos judiciais), mas apropriação, sim: não haveria, se se quer. advogados, mas o "direito" o suum, sim.

O mesmo pode ser dito da atribuição ou distribuição de funções dentro da sociedade: uns são policiais ou médicos, outros trabalham como padeiros: uns são políticos, outros agricultores. Nem todos padeiros e nem todos médicos.

A vida humana em sociedade exige que as coisas (bens, tarefas, encargos, etc.) estejam repartidas, atribuídas a diferentes sujeitos. Daí nasce o "meu" o "seu" o "dele" ou o "dela"... E se as coisas estão repartidas, então nem tudo é de todos: isso é algo lógico e corresponde a uma necessidade social.

Com isso, evidentemente, não estamos dizendo que a repartição de bens ou funções, tal como a encontramos numa determinada sociedade e num determinado momento histórico, não seja passível de críticas. Não se está esposando a tese de um conformismo com o status quo. Apenas estamos desenvolvendo a idéia de que existe um direito em sentido "objetivo" entendido como aquilo que corresponde ou é devido a alguém. E esse algo que é devido (o suum) nos reporta à idéia de "atribuição"

Quais são as "fontes" do Direito nesse sentido "objetivo"? Ou, por outras palavras, do que decorre a atribuição? Algo me pode ser devido, configurar um suum, (no caso seria um meum) em virtude da lei. Ou seja, a lei pode me atribuir coisas ou determinar que algo me é devido. Assim. a lei é sem dúvida fonte do Direito em sentido "objetivo". Mas, não é a única.

A atribuição e, por conseguinte, a determinação do Direito nessa acepção primeira de que estamos tratando, pode decorrer também das convenções e dos costumes. São também, então, fontes do Direito. Poderá se objetar dizendo que o contrato é "lei entre as partes", e que o costume nada mais é do que "a lei não-escrita" $\mathrm{Na}$ verdade, essas expressões constituem malabarismos terminológicos, dentro de uma ótica estritamente legalista, que reduz como já mencionado - o direito à lei.

E há, ainda. direitos que decorrem para cada um de nós da nossa condição de seres humanos. O direito à vida, à integridade física ou moral, as liberdades as mais variadas, etc., são via de regra contemplados nos ordenamentos jurídicos dos países ditos civilizados, são protegidos pela lei. Mas, a sua existência antecede à lei: decorrem. como afirmado, da nossa condição de seres humanos. O meu direito à vida ou a minha liberdade não são fruto de uma concessão do Estado, através do ordenamento jurídico vigente, mas exigências da minha dignidade de pessoa humana. São os direitos que 
antigamente se chamavam "naturais" e que modernamente são designados por "direitos humanos" ou "direitos fundamentais" Assim, pois a nossa condição humana deve ser considerada fonte, e até a fonte primeira, dos nossos direitos nesse sentido "objetivo" de que vimos falando.

Pelo exposto até aqui, das convenções. dos costumes, da lei e, sobretudo, da dignidade da nossa condição humana surge esse suum, esse "algo que nos é devido" A esse suum os antigos davam, numa acepção primeira, o nome de ius, do que podemos denominar "Direito em sentido objetivo" É o primeiro e genuíno dos diversos significados do termo "direito" Nessa visão das coisas "direito" e "lei" não se identificam, não são a mesma coisa.

4. O Direito em sentido "positivo": a norma agendi

Se "direito" é a coisa justa (ipsa res iusta), a coisa devida ou "o seu" (suum) que corresponde a uma pessoa, é também a denominação dada à "lei" em sentido amplo, à norma posta (norma agendi). Nesse caso, estamos falando do "Direito em sentido positivo" ou, também, do Direito posto, promulgado.

Ao longo da história, da antiguidade até hoje, o poder político, em suas múltiplas manifestações. levou a termo a promulgação de regras tendentes a disciplinar os mais variados aspectos da vida em sociedade. As Leis de Esnunna (por volta de 1930 a. C.), entre os acádios, ou o chamado Código de Hamurabi (ano 1694 a.C.. aproximadamente), na antiga Mesopotâmia, são exemplos disso.

$\mathrm{Na}$ Roma antiga, leis e plebiscitos, editos dos pretores, senatusconsultos ou constituições imperiais foram manifestações de um Direito "posto", promulgado, nos sucessivos períodos da sua longa história.

Essas diversas expressões do Direito positivo foram quase que totalmente reduzidas, no Baixo Império ou Dominato, ao conceito de lex, entendido nessa época não mais como o era no período republicano - expressão da soberania do povo -, mas como manifestação da vontade absoluta do soberano. Este modo de ver o "Direito positivo" ou posto e a lex, vai ser um dos legados da experiência política da Roma imperial para a posteridade.

Ao longo dos séculos. conforme o momento e o lugar, o poder de fazer leis vai mudar de mãos, e o direto positivo vai adquirir feições variadas. Mas em momento algum, a não ser em época recente. vai se dar ao termo "Direito" a conotação reducionista que tende a identificá-lo com "lei" 
Assim, ao lado das normas promulgadas, iremos encontrar esse sentido mais amplo do vocábulo "direito" entendido como "o que é devido a alguém" devido muitas das vezes em virtude da lei. mas outras, também, por força dos costumes de um determinado lugar, dos contratos ou dos acordos realizados entre o povo de uma dada população e a autoridade local.

No conceito de "Direito positivo" da lei em sentido amplo, o princípio não é o do Direito em sentido "objetivo", ou seja, o da repartição, mas o da ordenação das condutas. A lei, enquanto regra ditada pela autoridade estatal, tornada obrigatória para se manter a ordem e o progresso numa comunidade, tem como função própria a ordenação racional das condutas. Ordenar ou regular a vida social é tarefa dos governantes; por isso, são os órgãos políticos (congresso, governo, o próprio povo) os que fazem a leis. Fazer leis é atribuição dos políticos, é arte. a arte da política (ars politica) que a eles corresponde. e não propriamente aos juristas.

Nessa perspectiva, ao menos na intenção, as leis existem. são promulgadas pelas autoridades, na tentativa de ordenar as condutas, procurando construir assim a sociedade segundo a justiça. a liberdade ou a solidariedade. Essas leis são. em muitas ocasiões, fonte de um suum de alguém, ou seja, de um Direito em sentido "objetivo"

\section{O Direito em sentido "subjetivo": a facultas agendi}

Dos direitos, em sentido objetivo, decorrem faculdades para o seu titular: são os chamados "direitos subjetivos" Se alguém é proprietário de uma casa (e a propriedade é um tipo de direito), tem - deve ter - a faculdade de morar nela, se assim quiser; de vendê-la, se assim the convier; de demoli-la, se preferir, para construir uma nova em seu lugar; de exigir a sua devolução, se the tiver sido usurpada ou ilegalmente requisitada, etc. Quem tem "direitos" deve poder usufruir deles e dispor dos meios para torná-los efetivos.

$\mathrm{Na}$ antiga definição dos juristas medievais, a propriedade era vista como o ius utendi, fruendi et abutendi rem suam (direito de usar, fruir e dispor da sua coisa). Mas de quê adianta dizer que eu tenho um direito, se não posso torná-lo efetivo? Que sentido faz afirmar que eu sou proprietário, se não posso efetivamente usar, fruir ou dispor do que é meu? São essas faculdades que dão sentido ao "direito" que dizemos ter.

Dentre essas faculdades destaca-se, sem dúvida. a de exigir de terceiros um determinado comportamento, no sentido de respeitar aquilo que é o nosso direito. Quando esse respeito não surge espontâneo, temos então o direito de ação, de recorrer ao juiz, para que por seu intermédio recebamos o que nos corresponde. 
Para os juristas romanos, homens práticos e, como é sabido, avessos à teorização, os direitos se definiam mais pelas ações correspondentes do que propriamente pela descrição do seu conteúdo. Assim, por exemplo, ser locador era fundamentalmente poder dispor da actio locati; e ser proprietário, ter a possibilidade de reaver a sua coisa (res), mediante a rei vindicatio. Não por acas s, já houve quem definiu

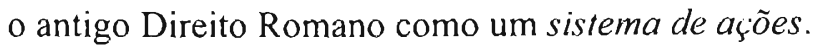

\section{A Justiça: suum cuique tribuere}

O pensamento clássico cunhou a célebre definição da justiça, entendida como "dar a cada um o que é seu" (suum), ou "dar a cada ur c seu direito" porque. como já visto, na sua acepção primeira, suum e "direito" são a mes na coisa.

Assim entendida, a justiça depende do Dirદito: do Direito e não simplesmente da norma. Isto supõe admitir a existência de direito:s inerentes à condição de pessoa humana: os tais "direitos fundamentais", mencionádos anteriormente. Eles podem ser entendidos como o conjunto (e, também cada um deles em particular) de direitos que o homem tem por si mesmo, e não por concessâo dos parlamentares, do governo ou da sociedade.

$\mathrm{Na}$ perspectiva dos direitos fundamentais, a insuficiência ou injustiça de uma determinada lei (e, nesse sentido, pode se falar, sim, em "lei injusta") se mede pela sua adequação, pelo seu respeito a esses direitos inerentes à pessoa humana. Um direito, de propriedade, por exemplo, pode não constituir exatamente um suum, como se pensa, se confrontado com exigências não-atendidas dos direitos fu idamentais de terceiros. Basta pensar naquilo que a doutrina, de há muito, denomina coıno "furto famélico" que pode ser considerado muito mais do que um simples excludente de tipicidade penal.

A justiça leva a dar a cada um "o seu" (suum), o que lhc corresponde, em função de uma repartição estabelecida pela natureza, pela lei, pelo costume ou pelas convenções. O que corresponde: nem mais, nem menos. Nesৎe sentido, deve-se dizer que a justiça é estrita. Fora disso existe, ou pode existir, a solidariedade, a amizade, a liberalidade, a generosidade, etc., atitudes ou virtudes importantes, sem dúvida, para a vida em sociedade, mas que não se confundem e em nada substituem o exercício da justiça. Por isso, quantas vezes uma pretensa "gencrosidade" ou "liberalidade" em matéria salarial, por exemplo, deveria ser desmascarada e encarada como exigência da estrita justiça...

A imagem da justiça evoca a idéia da igualdade. Contudo, deve-se salientar que a igualdade da justiça não se confunde com o iģualitarismo político, ou 
seja, a aspiração ou o ideal utópico de uma sociedade onde todos seriam iguais, receberiam as mesmas coisas, teriam todos o mesmo, etc.

Dois aspectos, na figura da deusa romana Iustitia, evidenciam os reclamos da igualdade: os olhos vendados e o equilíbrio da balança.

A Iustitia romana não é cega: tem os olhos cobertos por uma faixa, a simbolizar que não faz acepção de pessoas. Trata todos igualmente, porque a todos dá aquilo que thes corresponde, em virtude da lei, do contrato, etc. Não discrimina. Não repara na pessoa: olha unicamente o direito de cada um. Por isso, discriminações raciais, ou de sexo, nacionalidade, condição social ou econômica, etc., devem ser sempre consideradas uma injustiça.

Interessante notar que a deusa grega Dikê, de resto muito parecida com a sua correspondente romana. não tinha os olhos vendados, revelando a diferente concepção que, neste particular. impregnava a prática dos julgamentos naquelas terras. sendo levada em consideração a condição social ou o peso político das partes envolvidas num litígio.

O outro aspecto diz respeito à posição da balança: os pratos entram em equilibrio quando o conteúdo dos mesmos, o seu peso, se equivale. Perante essa equivalência, o fiel se mantém no meio, reto. Daí o "derectum" a que já fizemos referência anteriormente. A igualdade da justiça, então, se manifesta pela equivalência de pesos nos pratos da balança. Não é questão de dar a todos as mesmas coisas. mas de dar a todos, a cada um, igualmente, aquilo que the corresponde.

Assim. fazendo uma comparação, num hospital, igualdade não é dar a todos os doentes o mesmo remédio, mas dar a todos a mesma atenção, ou seja, a cada um o remédio exigido pela sua doença. A justiça leva a tratar todos igualmente naquilo em que são iguais, e de modo diferente naquilo em que são diferentes.

A reflexão sobre a justiça, e sobre a justiça relacionada com o Direito, foi feita na Grécia antiga por Aristóteles, no Livro V de sua célebre Ética a Nicômaco. Nele nos fala, entre outras coisas, de uma justiça das trocas e de uma justiça política, ambas impregnadas do sentido da igualdade.

A primeira delas, também chamada de justiçu comutativa, é a justiça do comércio. No açougue ou na feira, as mercadorias têm um preço. Numa compra e venda, o objeto é trocado, via de regra, pelo seu equivalente ou correspondente em dinheiro: um melão por duas moedas. Nesses casos, da justiça das trocas, Aristóteles fala de uma igualdade simples, aritméticu, que expressa com a fórmula " $\mathrm{a}=\mathrm{x}$ " onde " $\mathrm{a}$ " é a mercadoria. e " $\mathrm{x}$ " o seu equivalente em dinheiro. 
Em condições normais (deixando de lado situações particulares estabelecidas, por exemplo, por disposição legal), nas relações comerciais, a justiça leva a cobrar de todos o mesmo preço, independentemente de seu grau de instrução ou das suas preferências em matéria política ou esportiva: isso é o que significa "tratar todos igualmente naquilo em que são iguais"

No entanto, existem situações na vida da sociedade, em que as relações não podem ser resolvidas dessa forma. Seria justo pagar a todos o mesmo salário, sem levar em consideração a qualidade do seu serviço? Seria justo cobrar de todos o mesmo imposto, ignorando que uns têm ou ganham mais do que outros?

Aristóteles fala, então, da justiça distributiva. Neste caso, para o filósofo grego, a igualdade da justiça se expressa na forma de uma proporção: "a / x = b / y", onde "a" e "b" seriam as pessoas, e "x" e " $y$ " o que ele denomina de "mérito"

É justo que alguém que realiza um trabalho altamente especializado, para cuja consecução teve que despender muitas energias e tempo, receba por ele mais do que aquele que desempenha um trabalho sem maiores qualificações. É justo que dois trabalhos que requerem esforços diferentes, sejam diferentemente remunerados. Contudo, deve existir uma certa proporção. Essa proporção é a chave da justiça distributiva, ou se se quer, da justiça social, que diz respeito à distribuição dos ônus e vantagens da vida social.

Essa mesma reflexão, com a sua exigência de proporcionalidade, deveria permear toda a discussão sobre salário justo, imposio justo, etc. Uma sociedade, como um todo, será tanto mais justa quanto mais proporcional for o tratamento dado a essas questões.

Concluindo, podemos afirmar que o justo é tratar todos igualmente, naquilo em que são iguais, e de modo diferente, mas proporcional - esta é a chave da justiça social: a proporção--, naquilo em que são diferentes.

São Paulo. dezembro de 2006.

Referências

ALVES, José Carlos Moreira. Direito romano. 13. ed. Rio de Janeiro: Forense, 2002. v. I. . Direito romano. 6. ed. Rio de Janeiro: Forense, 2003. v. 2.

AQUINO, Thomas de. Suma Teológica Trad. de Alexandre Corrêa. 2. ed. Porto Alıgre, Escola Superior de Teologia Săo Lourenço de Brindes: Sulina, 1980. v. 4. 
ARISTÓTELES. Érica a Nicômacos. Brasília: Editora Universidade de Brasilia, 1985.

CRUZ, Sebastião. Ius Derectum (Dircctum). Coimbra, 1974.

DEL VECCHIO, Giorgio. Lições de Filosofia do Direito. 2. ed. Coimbra: Arménio Amado, 1951.

FARIA, Anacleto de Oliveira. Instituiçôes de Direito. 3. ed. São Paulo: Revista dos Tribunais, 1975.

FRANÇA, Rubens Limongi. O Direito, a Lei e a Jurisprudencia. São Paulo: Revista dos Tribunais, 1974.

GILISSEN, John. Introduction hustorique au droit. Bruxelles, Émille Bruyant, 1979. Trad. port. por A. M. Hespanha e L. M. Macaísta Malheiros. Introdução histórica ao Direito. Lisboa: Fundação Calouste Gulbenkian, 1988.

HERVADA, Javier; CUNHA. Paulo Ferteira da. Direitu: guia universitário. Porto: Rés Editora. s.d.

MARKY, Thomas. Curso clementar de Direito romano. 8. ed. São Paulo, Saraiva, 1995.

MONTORO, André Franco. Introdução à Ciência do Direito. 12 ed. São Paulo: Revista dos Tribunais, 1983. v. 1 .

POVEDA VELASCO. Ignacio Maria. Da lei injusta. Revista de Direito (ivil. Imobiliário, Agrário e Empresarial, São Paulo, v. 44, p. 125-143. 1988.

SCHULZ, Fritz. Prinzipen des römischen Rechts. München Duncker \& Humbolt. Trad. esp. por M. Abellán Velasco. Principios del derecho romano. Madrid: Civitas, 1990.

SILVEIRA, Alípio. Conceito e função da eqüidade em face do Direito positivo, especialmente do Direito civil. Direito, ano III, v. XVIII. p. 82-97, nov.-dez.

VILLEY, Michel. Filosofia do Direito: definições e fins do Direito. São Paulo: Atlas, 1977. - Le droil romain. Presses Universitaires de France. Trad. port. por Fernando Couto. Direiro romano. Porto: Rés F:ditora, s.d. 